\section{Heterochromatin distribution and histone modification patterns of H4K5 acetylation and H3S10 phosphorylation in Capsicum L.}

\author{
Lívia do Vale Martins ${ }^{1}$, Ana Paula Peron ${ }^{1}$, Ângela Celis de \\ Almeida Lopes ${ }^{1}$, Regina Lúcia Ferreira Gomes ${ }^{1}$, Reginaldo de \\ Carvalho $^{2}$ and Lidiane de Lima Feitoza ${ }^{1^{*}}$
}

\begin{abstract}
We evaluated domesticated Capsicum pepper species from Brazil using classical and molecular cytogenetic techniques, and describe here for the first time their immunostaining patterns using anti-H4K5ac and anti-H3S1Oph antibodies. All accessions showed $2 n=24$ chromosomes with metacentric and submetacentric morphologies. $C M A_{3}$ patterns ranged from four terminal bands in most accessions to 18 variable $C M A^{++} / D A P l^{-}$and $C M A^{+} / D A P I^{\circ}$ bands. AntiH4K5ac signals were detected in the decondensed terminal euchromatin of most chromosome arms, indicating gene-rich open chromatin regions. Anti-H3S1Oph signals were restricted to pericentromeric regions and were associated with sister chromatid cohesions and/or the condensation of all mitotic chromosomes. These karyological analyses constitute valuable diagnostic tools for identifying cultivated peppers, will be important to Capsicum breeding programs and will provide additional cytogenetic features that can be used for the conservation of capsicum genetic resources.
\end{abstract}

Key words: Cytogenetics, domesticated peppers, heterochromatic blocks, epigenetics.

\section{INTRODUCTION}

Understanding the genomic organization and chromosomal evolution of socioeconomically important crops is essential to characterizing their genetic diversity, and represents an important initial step in plant breeding programs (Scaldaferro et al. 2013). The genus Capsicum L. (Solanaceae) comprises approximately 35 species that are mostly classified as wild or semi-domesticated, with five taxa being cultivated worldwide: C. annuum L. var. annuum (bell pepper), C. baccatum L. var. pendulum (Willd.) Eshbaugh (ají), C. chinense Jacq. (habanero), C. frutescens L. (tabasco) and C. pubescens Ruiz and Pavon (rocoto) (Carrizo García et al. 2013).

Capsicum is native to the tropical and subtropical Americas, with Brazil being considered a secondary center of its genetic diversity (Mongkolporn and Taylor 2011). Peppers constitute part of the Brazilian cultural and genetic heritage and are cultivated throughout that country with a variety of local names, types, shapes, colors, flavors, pungencies and aromas (Reyes-Escogido et al. 2011). Capsaicin (8-methyl-N-vanillyl-6-nonanamide) is an alkaloid exclusive to
Crop Breeding and Applied Biotechnology 18: 161-168, 2018 Brazilian Society of Plant Breeding. Printed in Brazil http://dx.doi.org/10.1590/198470332018v18n2a23

70332018v18n2a23 
the capsicums, and their protein, vitamin and fiber contents lend them high nutritional value as well as antimicrobial, antioxidant, anti-inflammatory and anti-carcinogenic qualities (Singh and Jain 2016).

Despite their known socio-economic importance, our cytological knowledge of peppers is still incipient and further studies based on biochemical, molecular and cytogenetic techniques are needed (Moscone et al. 1993). Karyotype analysis is an important tool for characterizing Capsicum species (Moscone et al. 2007) and complements morphological, phytogeographical and molecular approaches. Cytogenetic data, associated with cytomolecular techniques and studies of karyotype evolution have aided in the correct delimitations of Capsicum - a monophyletic group with a complex taxonomy and numerous unresolved interspecific relationships (Sehr et al. 2013, Carrizo García et al. 2016).

There are two different basal chromosome numbers known for the genus: $x=12$ and $x=13$. Although no consensus exists yet concerning the ancestral chromosome number of that group, the presence of more symmetrical karyotypes among species showing $x=12$ has led to the assumption that it is the probable ancestral number for the genus, and that the more asymmetrical karyotypes with $x=13$ are derived. While $2 n=2 x=24$ species have symmetrical karyotypes, low DNA amount and simple heterochromatic banding patterns, $2 n=2 x=26$ species have asymmetric karyotypes and higher DNA and heterochromatin contents. Different inter- and intra-specific cytotypes are common and indicate very active processes of chromosome diversification in that group (Moscone et al. 2007, Teodoro-Pardo et al. 2007, Scaldaferro et al. 2013, Moreira et al. 2017).

The packing status of DNA associated with proteins can provide a better understanding of genetic and epigenetic regulation in eukaryotes, including vegetables (Heslop-Harrison and Schwarzacher 2011). Post-translational modifications on the N-terminal tails of histones play essential and distinct roles in chromosome organization (Marcon-Tavares et al. 2014). The acetylation of lysine 5 on histone $\mathrm{H} 4$ (one of the most well-studied modifications) is generally associated with actively transcribed open chromatin, and is directly involved in the control of chromatin replication (Zhang et al. 2015). The phosphorylation of serine 10 on histone $\mathrm{H} 3$ during mitosis and meiosis, on the other hand, seems to be associated with cell division control. The temporal and spatial distribution of H3S10ph is currently known only for few angiosperms, and immunostaining data is almost nonexistent for Capsicum.

Thus, in light of the need to provide more cytogenetic information concerning the genomic structures of peppers to aid breeding programs, we characterized accessions from the Capsicum Germplasm Active Bank at the Federal University of Piauí (BAGC-UFPI) using Giemsa staining, CMA/DAPI banding techniques and, for first time, immunostaining techniques using anti-H4K5ac and H3S10ph antibodies. Those immunostaining techniques should allow the identification and localization of modified histones associated with gene-rich regions (characterized by open chromatin; anti-H4K5ac) and regions of chromatid cohesion and/or chromosome condensation (anti-H3S1Oph) to provide detailed maps of those two markers in mitotic chromosomes of Capsicum and better define pepper karyotypes.

\section{MATERIAL AND METHODS}

\section{Plant materials}

Capsicum seeds were obtained from accessions held at BAGC-UFPI (Table 1).

\section{Chromosome preparation}

Root tips obtained from germinated seeds were pretreated with $\mathrm{p}$-dichlorobenzene $\left(0.015 \mathrm{~g} \mathrm{~mL}^{-1}\right)$ for 2 hours at room temperature and then fixed in Carnoy (ethanol: acetic acid v/v) for at least 12 hours at $-20^{\circ} \mathrm{C}$.

\section{Conventional staining}

Slide preparation followed the methodology described by Guerra (2002). Root tips were hydrolyzed in $5 \mathrm{~N} \mathrm{HCl}$ for 20 minutes at room temperature and then squashed in $45 \%$ acetic acid. The slides were subsequently frozen in liquid nitrogen, stained with Giemsa for 10-15 min and mounted with Entellan (Merck).

\section{CMA/DAPI fluorochrome staining}

The protocol described by Schweizer and Ambros (1994) was followed, with minor modifications. Root tips were 


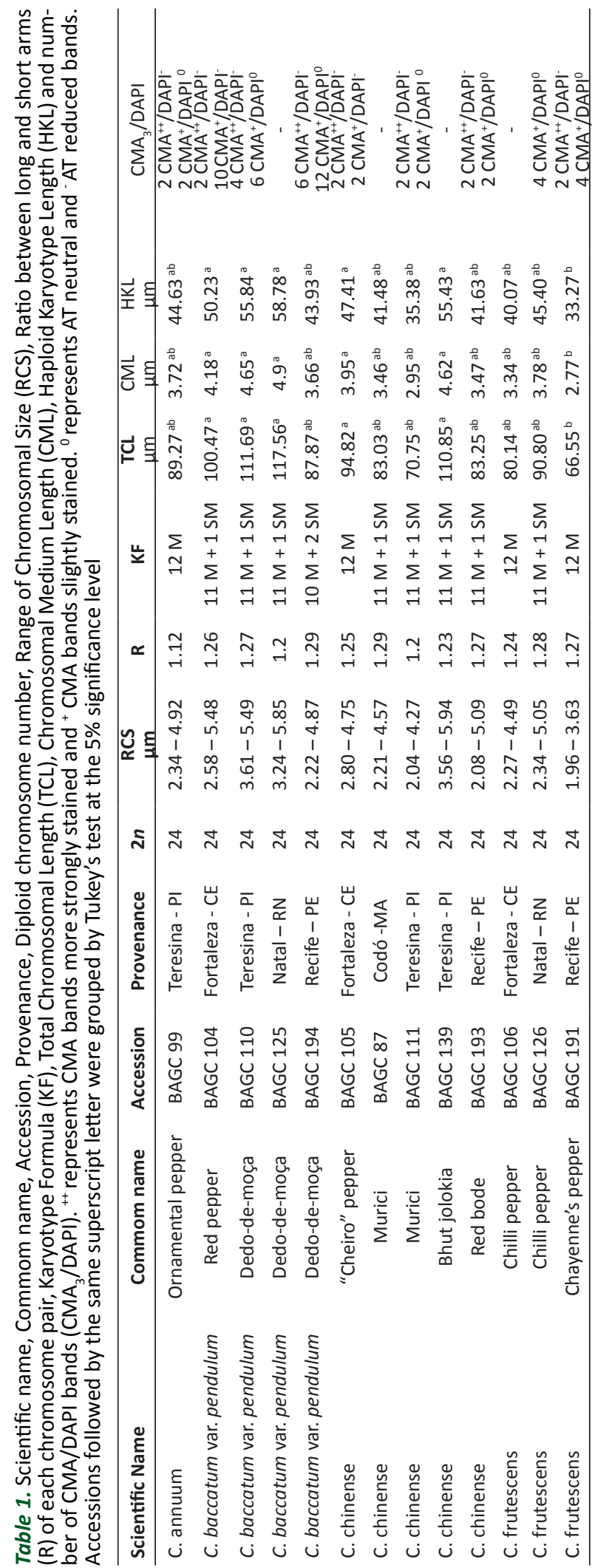

digested with $2 \%$ cellulase (Onozuka R-10) and $20 \%$ pectinase (Sigma). The slides were stained with $10 \mu \mathrm{L}$ of CMA $\left(0.5 \mathrm{mg} \mathrm{mL}^{-1}\right)$ for $1 \mathrm{~h}$, counterstained with $10 \mu \mathrm{l}$ of DAPI ( $2 \mathrm{mg} \mathrm{mL}^{-1}$ ) for $30 \mathrm{~min}$, mounted in glycerol/Mcllvaine (1:1) and stored for three days before analysis.

\section{Immunostaining with H4K5ac and H3S1Oph antibodies}

The immunostaining technique followed the protocol of Feitoza and Guerra (2011a). Roots tips fixed in 4\% paraformaldehyde were washed in $1 \times$ PBS and incubated overnight at $4{ }^{\circ} \mathrm{C}$ with the primary anti-H4K5ac and anti-H3S10ph antibodies (rabbit polyclonal IgG-Upstate Biotechnology, USA) diluted 1:300 in 1× PBS containing 3\% $B S A$. To detect the primary antibodies, $15 \mu \mathrm{L}$ of secondary antibody FITC-conjugated goat anti-rabbit IgG (Sigma) diluted 1:60 in 3\% BSA was added, and the root tips held in a dark chamber at room temperature for 3 hours. The preparations were then mounted in DAPI $\left(2 \mathrm{mg} \mathrm{mL}^{-1}\right)$ : Vectashield (1:1 v/v) and immediately photographed.

\section{Image analyses and morphometry}

The best five metaphases of each accession were photographed using a DFC345Fx digital camera coupled to a Leica DM2500 microscope. The images were adjusted and optimized for brightness and contrast using Adobe Photoshop CS3. Chromosome sizes were determined using the Micromeasure 3.3 program supplemented by Microsoft Excel 2010 software. Idiograms were constructed using Corel Draw X7 and chromosome morphologies were classified according to Guerra (1988).

\section{RESULTS AND DISCUSSION}

Conventional staining allowed a detailed description of the interphase nuclei, prophase condensation patterns, chromosome numbers, as well as chromosome morphologies and sizes (Figure 1, Table 1). Giemsa staining revealed semi-reticulate nuclei (Figure 1a) and Solanum-type prophase condensation pattern (CP) with early condensed proximal regions and late condensing terminal chromatin (Feitoza Costa and Guerra 2017). All accessions showed $2 n=24$ chromosomes, with metacentric and submetacentric morphologies. As reported by Moscone et al. (2007), all domesticated Capsicum taxa have a chromosome base number $x=12$ with symmetrical karyotypes, while other semi-domesticated and several wild species (such as C. campylopodium, C. villousum and C. buforum) have $\mathrm{x}=13$ with asymmetrical karyotypes that are probably derived from centric fissions (Robertsonian). 
Most accessions (BAGC 87, 104, 110, 111, 125, 126, 139, and 193, see table 1) showed the karyotype formula 11M + 1SM, while BAGC 99 (C. annuum), 105 (C. chinense) and 106 and 191 (C. frutescens) showed 12M; only the accession BAGC 194 (C. baccatum var. pendulum) showed $10 \mathrm{M}+2 \mathrm{SM}$. Chromosome sizes (RCS) ranged from $1.96 \mu \mathrm{m}$ in C. frutescens (BAGC 191) to $5.94 \mu \mathrm{m}$ in C. chinense (BAGC 139), while total chromosomal lengths (TCL) ranged from $66.55 \mu \mathrm{m}$ in $C$. frutescens (BAGC 191) to $117.56 \mu \mathrm{m}$ in C. baccatum var. pendulum (BAGC 125) Previous workers (Moscone et al. 1996) reported TCL variations from $122.62 \mu \mathrm{m}$ in $C$. chinense to $148.62 \mu \mathrm{m}$ in C. baccatum var. pendulum. Similarly, other $C$. annuum accessions from the Capsicum germplasm bank in Mexico showed high TCL polymorphisms, demonstrating the high inter- and intraspecific chromosome diversity found in Capsicum (Teodoro-Pardo et al. 2007). The observed differences in chromosome sizes of the different accessions could be related to unequal degrees of chromosome contraction during cell division (Moscone 1990), differences in pretreatment and chromosome condensation (Pozzobon et al. 2006), and/ or to different classes of repetitive DNA sequences as evolutionary components of pepper genome structures based on constitutive heterochromatin expansions (Shcherban 2015, Scaldaferro et al. 2016).

The double-staining technique with CMA and DAPI fluorochromes allowed the identification of three different heterochromatic banding patterns: highly GC-rich and AT-reduced $\left(\mathrm{CMA}^{++} / \mathrm{DAPI}\right)$; moderately GC-rich and AT-reduced $\left(\mathrm{CMA}^{+} / \mathrm{DAPI}\right)$; moderately GC-rich and AT-neutral $\left(\mathrm{CMA}^{+} / \mathrm{DAPI}^{\circ}\right)$ (Table 1, Figure 2). Differences in the numbers, patterns, and intensities of heterochromatic bands were observed. Four CMA bands were observed in two chromosome pairs in C. annuum (BAGC 99) and C. chinense (BAGC 111 and 193), with at least one pair of larger CMA $^{++}$bands and one pair of small $\mathrm{CMA}^{+}$bands. C. frutescens (BAGC 126) showed four $\mathrm{CMA}^{++}$bands, while BAGC 191 exhibited six bands (two $\mathrm{CMA}^{++} / \mathrm{DAPI}^{-}$and four smaller additional $\mathrm{CMA}^{+} / \mathrm{DAPI}^{\circ}$ bands). All of the accessions that showed variable numbers of heterochromatic bands (10, 12 and $18 \mathrm{CMA}^{++} / \mathrm{DAPl}^{-}$and $\mathrm{CMA}^{+} / \mathrm{DAPI}^{\circ}$ bands) were $C$. baccatum var. pendulum accessions (BAGC 110, 104 and 194 respectively). None of the accessions showed visible DAPI ${ }^{+}$bands. The idiograms in Figure 3 present graphic karyotype representations of each accession.

GC-rich heterochromatin is universal in Capsicum, appearing in all taxa with $x=12$; although located mainly in terminal regions, it may also occur in variable numbers of small intercalary and distal bands that are difficult to detect (as in C. chacoense, C. annuum var. glabriusculum, C. recurvatum, C. villosum and C. flexuosum) (Scaldaferro et al. 2013). Heterochromatin distribution is not always homogeneous within or among species, and polymorphisms have been reported (reviewed by Guerra 2000). Moscone et al. (1993) observed centromeric, distal, and intercalary bands unequally distributed in both chromosome arms of peppers. Those authors classified domesticated species into two groups based on their C-band contents: the white-flowered group ( $C$. annuum, $C$. chinense, and C. frutescens) with low heterochromatin contents, small terminal bands and lacking intercalary bands; and the purple-flowered group (which includes C. campylopodium and C. pubescens) with high heterochromatin contents, large telomeric bands and intercalary blocks. Although $C$. baccatum belongs to the white-flowered subgroup, it differs from the other three domesticated species by showing a complex heterochromatin pattern and longer chromosome lengths. We note here that $C$. baccatum var. pendulum exhibits higher numbers of heteromorphic GC-rich bands as compared to $C$. annuum, $C$. chinense, and $C$. frutescens.

For a better understanding of chromatin structural patterns and cell cycles in Capsicum, we performed

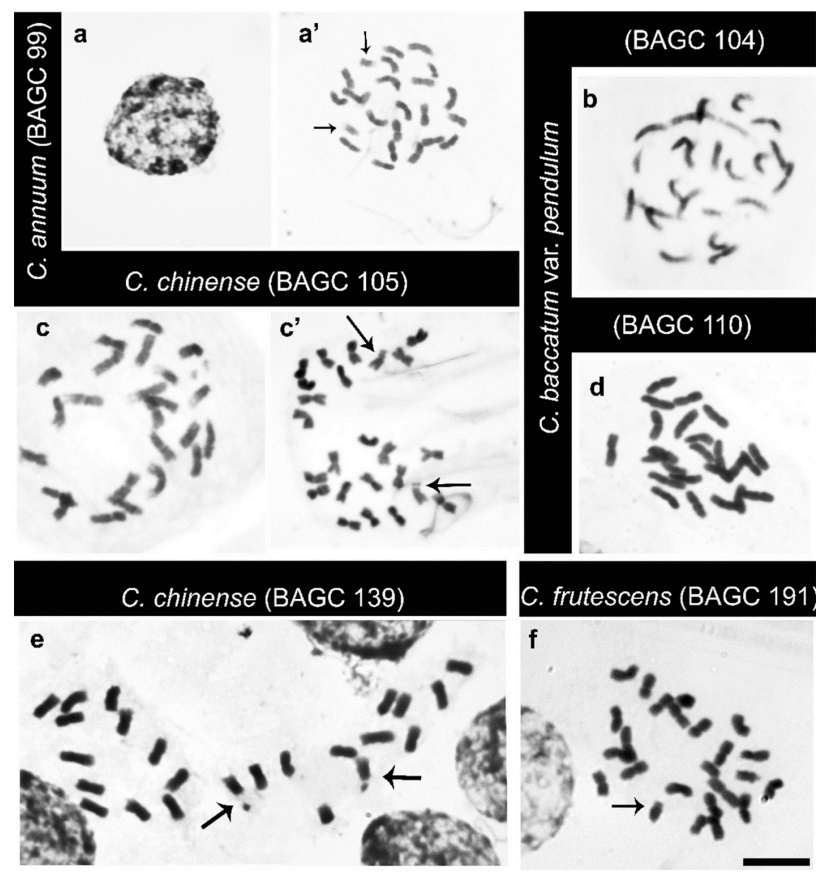

Figure 1. Chromosome number of prometaphase and metaphase in Capsicum sp. by Giemsa staining. a- interphase nucleus; a'prometaphase with arrows indicating chromosomic pair with decondensed chromatin in terminal region; $b, c$ - prometaphase; $c^{\prime}, d$, e and $f-$ metaphase. Arrows in $c^{\prime}$, e and $f$ indicate NORs. Bar $=10 \mu \mathrm{m}$. 
immunostaining using antibodies against histones modified by the acetylation of lysine 5 of histone $\mathrm{H} 4$ ( $\mathrm{H} 4 \mathrm{~K} 5 \mathrm{ac}$ ) and the phosphorylation of serine 10 of histone H3 (H3S10ph).

Anti-H4K5 patterns were classified as Solanum-type (Feitoza Costa and Guerra 2017), with labeling restricted to diffuse chromatin of the nuclei and in the decondensed terminal euchromatin of most mitotic chromosomes, from prophase-metaphase (Figure 4); the chromocenters of the interphase nuclei (and some terminal heterochromatic regions) were not stained. The acetylation patterns we observed showed labeling tightly associated with terminal open chromatin in the mitotic chromosomes of $C$. baccatum var. pendulum and $C$. chinense. Similar labeling has been reported in other plants with small chromosomes and wellestablished condensation pattern, such as Costus spiralis, Eleutherine bulbosa (Feitoza and Guerra 2011b) and $P$. vulgaris (Fonseca et al. 2014). The fact that anti-H4K5ac markings were present in all of the cell cycle phases analyzed suggests their close relationships with chromatin dynamic states that may change during the cell cycle and become restricted to specific chromosome sites during meiosis (Feitoza and Guerra 2011b).

Additionally, hyperacetylated regions (immunostaining marking) coincided with late condensing euchromatic regions (conventional staining), while hypoacetylated or nonacetylated regions were directly linked to early condensing prophase chromatin and to $\mathrm{CMA}^{++}$or $\mathrm{CMA}^{+}$blocks (CMA/ DAPI staining). As suggested by Dhar et al. (2009), acetylation patterns are inversely related to heterochromatic patterns: late replicating euchromatin (including heterochromatin) is early condensing, whereas early replicating chromatin
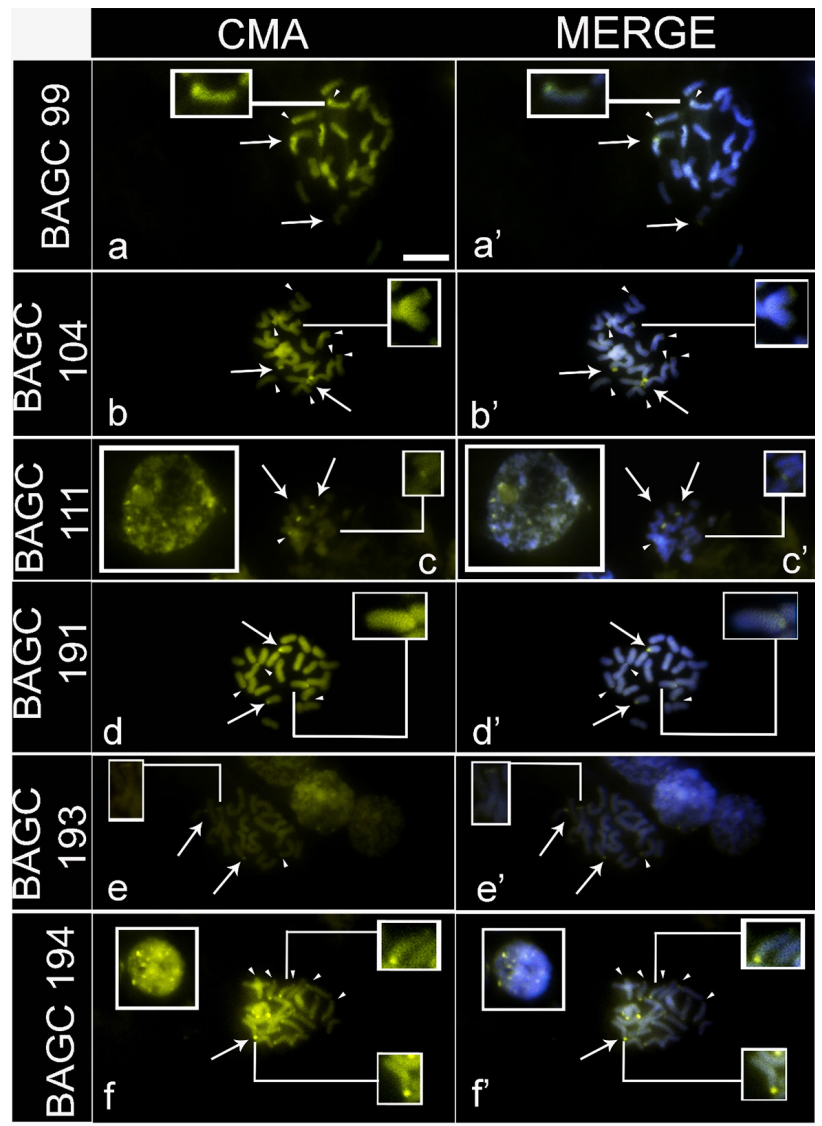

Figure 2. Double staining with $\mathrm{CMA}$ and DAPI fluorochromes in Capsicum accessions. a - C. annuum (BAGC 99); $b$ and $f-C$. baccatum var. pendulum (BAGC 104 and 194); c and e - C. chinense (BAGC 111 and 193); $d$ - C. frutescens (BAGC 191). Arrows indicate large $\mathrm{CMA}^{++}$blocks. Arrowheads indicate small $\mathrm{CMA}^{+}$blocks in terminal region difficult to detect, enlarged in all inserts. Bar $=10 \mu \mathrm{m}$.

(gene-rich euchromatin) is late condensing.

Since $\mathrm{H} 4 \mathrm{~K} 5$ acetylation is universally associated with gene expression and open chromatin (as observed in tomatoes [Cigliano et al. 2013], Silene and Allium cepa [Chang et al. 2008]), we believe that its labelling in uncondensed euchromatin is related to potentially active regions in the chromosomes of Capsicum.

Anti-H3S10ph signals, on the other hand, were restricted to the pericentromeric regions of all of the chromosomes during prometaphase-metaphase, while interphase nuclei were not stained (Figure 5). This pattern is associated with mitotic condensation and/or chromatid cohesion regardless of eu- and heterochromatin regions involved (unlike the pattern observed for anti-H4K5 markings). That phosphorylation marking only occurred in pericentromeric regions of the A chromosomes in Cestrum strigilatum (another Solanaceae species), although an exception was observed in its B chromosomes (Fernandes et al. 2008).

These results, associated with previous work performed in other socio-economically important crops, reinforce the idea that the hyperacetylation of $\mathrm{H} 4 \mathrm{~K} 5$ can be used as a chromosome marker for detecting active euchromatin associated with gene expression. $\mathrm{H} 3 \mathrm{~S} 10$ phosphorylation seems to be involved in regulating sister chromatid cohesion, although further studies will be needed. Our results demonstrated the feasibility of using immunostaining to detect gene-rich and pericentromeric regions during the cell cycle of Capsicum that could be used in future studies involving cytomolecular mapping and contribute to the genetic improvement of peppers and their preservation in Brazil. 


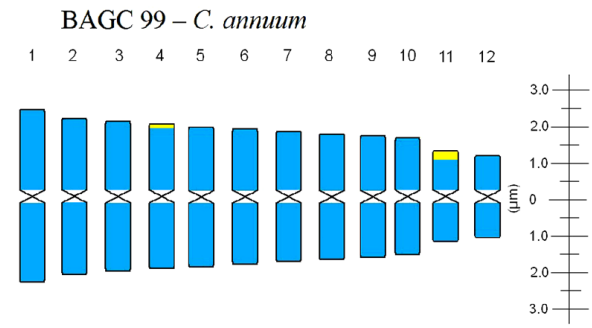

$\begin{array}{lllllllllllll}4.92 & 4.44 & 4.27 & 4.13 & 3.97 & 3.85 & 3.72 & 3.61 & 3.46 & 3.33 & 2.59 & 2.34 & \text { Size }(\mu \mathrm{m})\end{array}$

BAGC $110-C$. baccatum var. pendulum

\begin{tabular}{llllllllllll}
1 & 2 & 3 & 4 & 5 & 6 & 7 & 8 & 9 & 10 & 11 & 12 \\
\hline
\end{tabular}

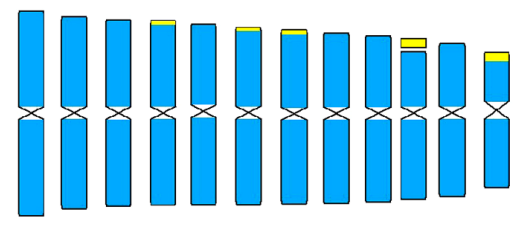

$\begin{array}{llllllllllll}5.49 & 5.15 & 5.00 & 4.94 & 4.84 & 4.75 & 4.65 & 4.56 & 4.44 & 4.30 & 4.10 & 3.61\end{array}$ BAGC $105-C$. chinense

$\begin{array}{llllllllllll}1 & 2 & 3 & 4 & 5 & 6 & 7 & 8 & 9 & 10 & 11 & 12\end{array}$

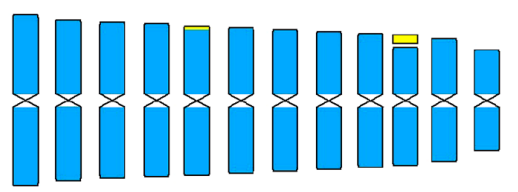

$\begin{array}{llllllllllll}4.75 & 4.47 & 4.33 & 4.27 & 4.16 & 4.04 & 3.93 & 3.83 & 3.73 & 3.62 & 3.44 & 2.80\end{array}$

BAGC $193-C$. chinense
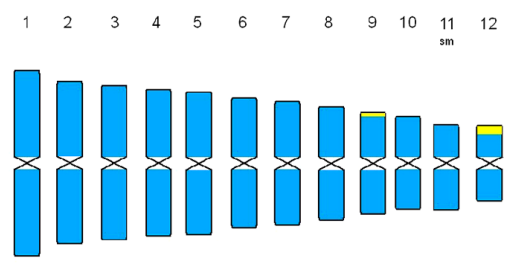

$\begin{array}{llllllllllll}5.09 & 4.46 & 4.23 & 4.04 & 3.93 & 3.58 & 3.38 & 3.13 & 2.79 & 2.55 & 2.34 & 2.08\end{array}$ BAGC $191-C$. frutescens

$\begin{array}{llllllllllll}1 & 2 & 3 & 4 & 5 & 6 & 7 & 8 & 9 & 10 & 11 & 12\end{array}$

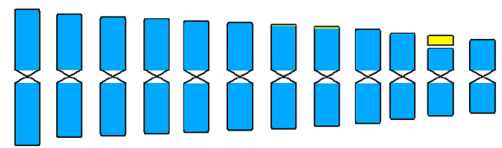

BAGC $104-$ C. baccatum var. pendulum

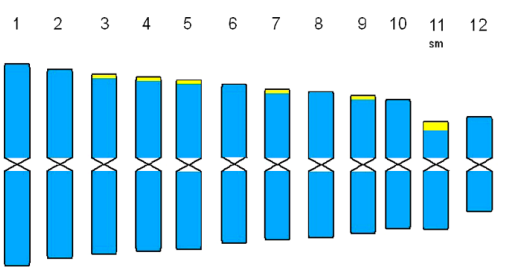

$\begin{array}{llllllllllll}5.48 & 5.13 & 4.90 & 4.75 & 4.61 & 4.33 & 4.11 & 3.96 & 3.77 & 3.51 & 3.09 & 2.58\end{array}$ BAGC 194 - C. baccatum var. pendulum

$\begin{array}{llllllllllll}2 & 2 & 3 & 4 & 5 & 6 & 7 & 8 & 9 & 10 & \substack{11 \\ \mathrm{sm}} & 12\end{array}$

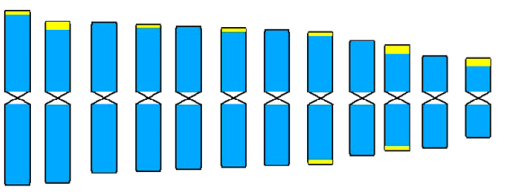

$\begin{array}{llllllllllll}4.87 & 4.50 & 4.20 & 4.10 & 3.97 & 3.90 & 3.77 & 3.69 & 3.20 & 2.94 & 2.56 & 2.22\end{array}$ BAGC $111-C$. chinense

$\begin{array}{llllllllllll}1 & 2 & 3 & 4 & 5 & 6 & 7 & 8 & 9 & 10 & 11 & 12\end{array}$

sm

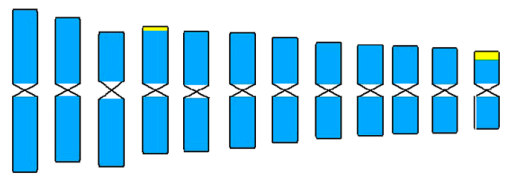

$\begin{array}{llllllllllll}4.27 & 3.78 & 3.54 & 3.32 & 3.15 & 3.03 & 2.77 & 2.52 & 2.40 & 2.30 & 2.24 & 2.04\end{array}$ BAGC $126-C$. frutescens

$\begin{array}{llllllllllll}1 & 2 & 3 & 4 & 5 & 6 & 7 & 8 & 9 & 10 & 11 & 12\end{array}$

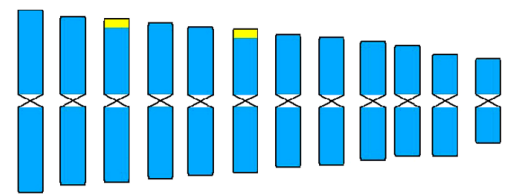

$\begin{array}{llllllllllll}5.05 & 4.67 & 4.53 & 4.32 & 4.11 & 3.96 & 3.68 & 3.53 & 3.28 & 3.07 & 2.83 & 2.34\end{array}$

$\begin{array}{llllllllllll}3.63 & 3.28 & 3.15 & 3.05 & 2.96 & 2.87 & 2.78 & 2.65 & 2.51 & 2.30 & 2.13 & 1.96\end{array}$

Figure 3. Idiograms representing size, morphology and distribution of $\mathrm{CMA}^{++}$terminals bands (larger yellow bands) and $\mathrm{CMA}^{+}$bands (smaller yellow bands) on chromosome of Capsicum's accessions. 


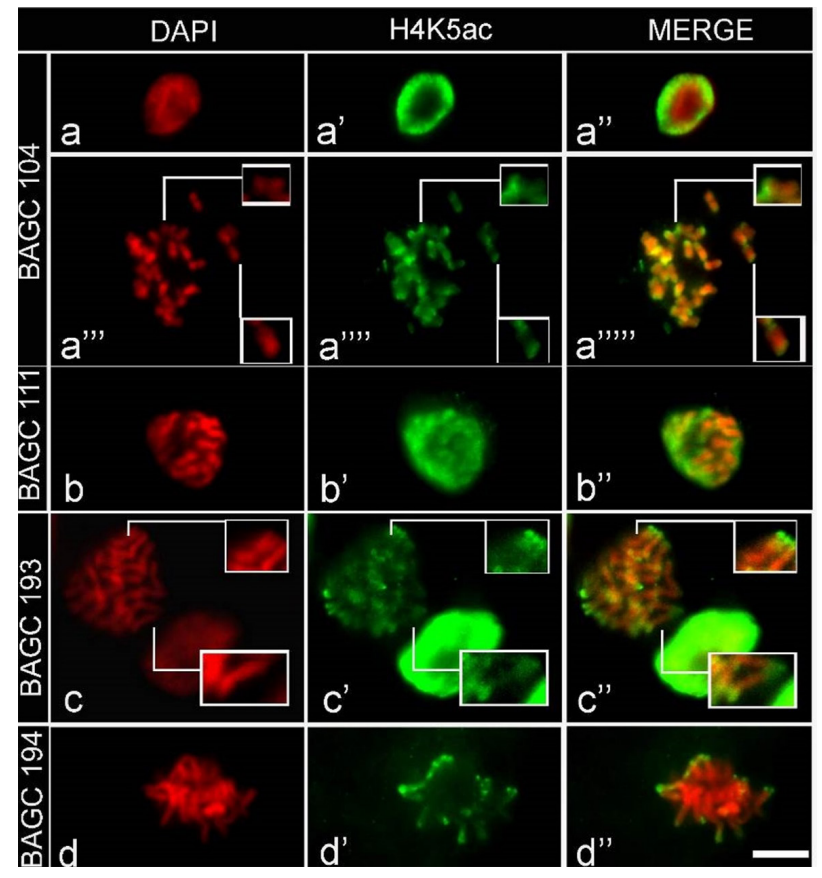

Figure 4. Immunostaining with anti-H4K5ac antibody in C. baccatum var. pendulum (BAGC 104 and 194) and C. chinense (BAGC 111 and 193). a, -a"'-interphase nucleus; $a^{\prime \prime \prime}$ - $a^{\prime \prime \prime \prime \prime \prime}$ - metaphase; b- prophase and c-d" - prometaphase showing terminal chromatin strongly marked (green) compared with condensed chromatin (red). Upper inserts indicate chromosome with terminal region strongly acetylated on one terminal arm, while lower inserts indicate chromosome with terminal regions strongly acetylated on both arms (green). DAPI pseudocolored in red and anti-H4K5ac in green. Bar $=10 \mu \mathrm{m}$.

\section{REFERENCES}

Carrizo García C, Barfuss MHJ, Sehr EM, Barboza GE, Samuel R, Moscone EA and Ehrendorfer $F$ (2016) Phylogenetic relationships, diversitifcation and expansion of chilli peppers (Capsicum, Solanaceae). Annals of Botany 118: 35-51.

Carrizo García C, Sterpetti M, Colpi P, Ummarino M and Saccardo F (2013) Wild capsicums: identification and in situ analysis of Brazilian species of Capsicum. In Breakthroughs in the genetics and breeding of Capsicum and eggplant. Eucarpia, Turin, p. 205-213.

Chang SB, Yang TJ, Datema E, Vugt JV, Vosman B, Kuipers A, Meznikova M, Szinay D, Lankhorst RK, Jacobsen E and de Jong H (2008) FISH mapping and molecular organization of the major repetitive sequences of tomato. Chromosome Research 16: 919-933.

Cigliano RA, Sanseverino W, Cremona G, Ercolano MR, Conicella C and Consiglio FM (2013) Genome-wide analysis of histone modifiers in tomato: gaining and insight into their developmental roles. BMC Genomics 14: 57.

Dhar MK, Fuchs J and Houben A (2009) Distribution of eu- and heterochromatin in Plantago ovata. Cytogenetic and Genome

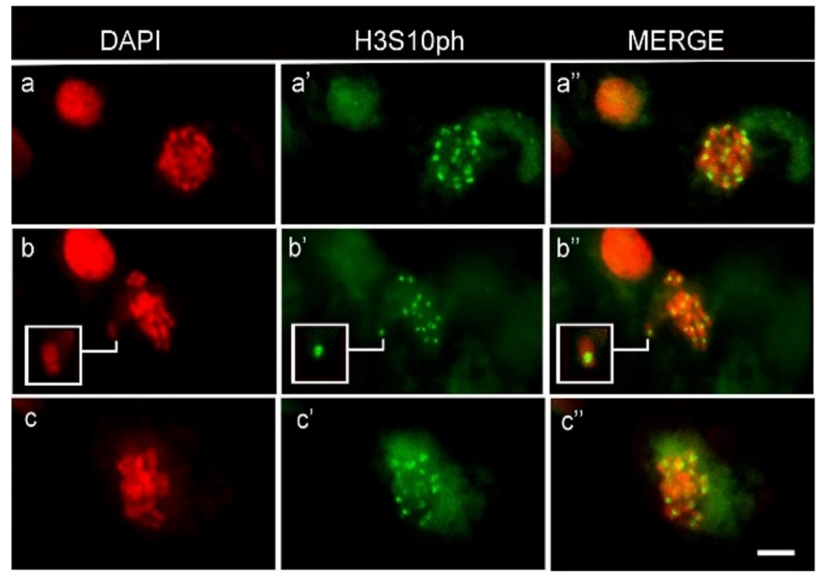

Figure 5. Immunostaining with anti-H3S10ph antibody in prometaphase chromosome of: a - C. annuum (BAGC 99), b - C. chinense (BAGC 111) and c - C. baccatum var. pendulum (BAGC 125). Observe intense staining of antibody (green) in pericentromeric region (insert in b). Interphase nuclei in the left corner on a and b were not marked. Bar $=10 \mu \mathrm{m}$.

\section{ACKNOWLEDGMENTS}

We would like to thank the Brazilian agency CNPq (Conselho Nacional de Desenvolvimento Científico e Tecnológico/process number 457201/2014-2) for financial support.

Research 125: 235-240.

Feitoza L and Guerra M (2011a) Different types of plant chromatin associated with modified histones $\mathrm{H} 3$ and $\mathrm{H} 4$ and methylated DNA. Genetica 139: 305-314.

Feitoza L and Guerra M (2011b) The Centromeric Heterochromatin of Costus spiralis: Poorly Methylated and Transiently Acetylated during Meiosis. Cytogenetic and Genome Research 135: 160-166.

Feitoza L, Costa L and Guerra M (2017) Condensation patterns of prophase/prometaphase chromosome are correlated with H4K5 histone acetylation and genomic DNA contents in plants. Plos One 12(8): e0183341.

Fernandes T, Yuyama PR, Moraes AP and Vanzela ALL (2008) An uncommon $\mathrm{H} 3 / \mathrm{Ser} 10$ phosphorylation pattern in Cestrum strigilatum (Solanaceae), a species with B chromosomes. Genome 51: 772-777.

Fonseca A, Richard MS, Geffroy V and Pedrosa-Harand A (2014) Epigenetic Analyses and the Distribution of Repetitive DNA and Resistance Genes Reveal the Complexity of Common Bean (Phaseolus vulgaris L., Fabaceae) Heterochromatin. Cytogenetic and Genome Research 143: 168-178. 


\section{Martins et al.}

Guerra M (2000) Patterns of heterochromatin distribution in plant chromosomes. Genetics and Molecular Biology 23: 1029-1041.

Guerra M (2002) Como observar cromossomos: um guia de técnicas em citogenética vegetal, animal e humana. FUNPEC, Ribeirão Preto, 131p.

Guerra MS (1988) Introdução à citogenética geral. Guanabara Koogan, Rio de Janeiro,140p.

Heslop-Harrison JSP and Schwarzacher T (2011) Organisation of the plant genome in chromosomes. The Plant Journal 66: 18-33.

Marcon-Tavares AB, Felinto F, Feitoza L, Barros e Silva AE and Guerra M (2014) Different patterns of chromosomal histone $\mathrm{H} 3$ phosphorylation in land plants. Cytogenetic and Genome Research 143: 136-143.

Mongkolporn O and Taylor PWJ (2011) Capsicum. In Kole C (ed) Wild crop relatives: genomic and breeding resources. Springer-Verlag, Berlin Heidelberg, vol. 5, p. 43-57.

Moreira NF, Pereira TNS and Martins KC (2017) Meiotic analysis of interspecific hybrids between Capsicum frutescens and Capsicum chinense. Crop Breeding and Applied Biotechnology 17: 159-163.

Moscone EA (1990) Chromosome studies on Capsicum (Solanaceae) I. Karyotype analysis in C. chacoense. Brittonia 42: 147-154.

Moscone EA, Lambrou M, Hunziker AT and Ehrendorfer F (1993) Giemsa C-banded karyotypes in Capsicum (Solanaceae). Plant Systematics and Evolution 186: 213-229.

Moscone EA, Matzke MA and Matzke AJM (1996) Fluorescent chromosome banding in the cultivated species of Capsicum (Solanaceae). Plant Systematics and Evolution 202: 37-63.

Moscone EA, Scaldaferro MA, Gabriele M, Cecchini NM, García SY, Jarret R, Davinã JR, Ducasse DA, Barboza GE and Ehrendorfer F (2007) The evolution of chili pepers (Capsicum - Solanaceae): a cytogenetic perspective. Acta Horticulturae 745: 137-170.
Pozzobon MT, Schifino-Wittmann MTA and Bianchetti LB (2006) A meiotic study of the wild and semi-domesticated Brazilian species of genus Capsicum L. (Solanaceae). Cytologia 71: 275-287.

Reyes-Escogido ML, Gonzales-Mongradon EG and Gonzales-Mongradon E (2011) Chemical and pharmacological aspects of capsaicin. Molecules 16: $1253-1270$.

Scaldaferro MA, da Cruz VR, Cecchini NM and Moscone EA (2016) FISH and AgNor mapping of the $45 \mathrm{~S}$ and $5 \mathrm{~S}$ rRNA genes in wild and cultivated species of Capsicum (Solanaceae). Genome 59: 95-113.

Scaldaferro MA, Gabriele M and Moscone EA (2013) Heterochromatin type, amount and distribution in wild species of chilli peppers (Capsicum, Solanaceae). Genetic Resources and Crop Evolution 60: 693-709.

Schweizer D and Ambros PE (1994) Chromosome banding stain combinations for specific regions. In: Chromosome analysis protocols. Humana Press 29: 97-112.

Sehr EM, Ehrendorfer F, Barfuss MHJ, Barboza GE, Moscone EA and Samuel R (2013) Phylogenetic relationships and dysploidy in Capsicum: evidence from DNA sequences and other multidisciplinary data. Global Systematics 2: 193-194.

Shcherban AB (2015) Repetitive DNA sequences in plant genomes. Russian Journal of Genetics: Applied Research 5: 159-167.

Singh D and Jain R (2016) Nutritive and medicinal value of capsicum. Journal of Medical Society 30: 69.

Teodoro-Pardo CV, García-Velázquez A and Corona-Torres T (2007) Polimorfismo cromossómico en Capsicum annuum L. (Solanaceae) en recolectas de Puebla, Morelos y Quartenário, México. Agrociencia 41: 873-881.

Zhang W, Garcia N, Feng Y, Zhao H and Messing J (2015) Genome-wide histone acetylation correlates with active transcription in maize. Genomics 4: 214-220. 